\title{
The Prevalence of Overweight and Obesity among 7-8 Years Old Children of Tirana City
}

\author{
Elvira Baze \\ Institute for Educational Development, Str. "Naim Frashëri", no 37, Tirana, Albania, \\ elvirabaze74@yahoo.co.uk/elvirabaze74@gmail.com
}

\author{
Doi:10.5901/mjss.2013.v4n10p388
}

\begin{abstract}
This topic intends to bring to the attention of the audience data on the situation of one of the components of fitness to children, on Body Composition. The study aims to observe contemporary trends of overweight and obesity among children of 7-8 years old evaluating the prevalence of this phenomenon. The subjects of the study are 1500 primary school children in Tirana, capital of Albania. The methodology is based on the measurement of fat percentage. Data analysis brings to attention a least favorable situation with regard to the prevalence of this phenomenon in this age group. If the body composition is not in appropriate reports, the child does not enjoy the fitness condition. Moreover, overweight and obesity are associated with serious complications and diseases in childhood, while overweight and obese children tend to become overweight and obese adults risking numerous diseases. The genetic predisposition factor and the daily dietary intake (the way of nutrition) have not changed over the last decades, while the indicators of overweight and obesity have increased in value, making daily physical inactivity the main cause for the rapid growth of this phenomenon at this age. A child who regularly practices physical activity, when he will grow up, will be much more favored than those who rarely or never practice it, he would have won a state of optimal body composition, will be able to afford daily requirements with the desire and energy, enjoying the so-called FITNESS.
\end{abstract}

Keywords: prevalence, body composition, fitness, obesity, physical inactivity.

\section{Introduction}

The number of overweight or obese people has significantly increased in recent decades. Results of recent scientific studies show that the prevalence of obesity has increased dramatically worldwide, this problem is significantly affecting all ages, adults as well as children. Data on the prevalence of obesity in the world of the World Health Association through MONICA project (Monitoring of trends and determinants in cardiovascular Diseases study) indicate that in most European countries, the prevalence of obesity has registered an increase of 10 to $40 \%$ in the last 10 years, varied between $10-20 \%$ of men and $10-25 \%$ among women ${ }^{1}$. But this phenomenon is already widespread in many countries even in those in the path of development like Albania, by expanding dangerously the prevalence map, being transformed into a real pandemic.

Obesity is an abnormal accumulation ever-increasing of the adipose tissue in that levels that are harmful to health. This condition use to be considered as a predisposition for diseases, but nowadays it is considered as a disease in itself by the specialists of Public Health and Physical Education, one of the their work priorities is the promotion of the fitness.

According to the President of the American Council of Physical Fitness and Health, fitness is: "The ability to perform daily tasks vigorously and alertly, with energy left over for enjoying leisure-time activities and meeting emergency demands. Is the ability to endure, to bear up, to withstand stress, to carry on in circumstances where an unfit person could not continue, and is a major basis for good health and well-being"2. Also, the American National Association of Sports and Physical Education fitness describes fitness as "a condition where the body is in a state of well-being and really able to meet the physical challenges of everyday life" 3 . The components of fitness in children are: cardiorespiratory endurance (aerobic capacity), muscular strength, muscular resistance, flexibility and body composition, the observation and study of which is very important nowadays. Body composition is the final component of fitness. This

\footnotetext{
1 Journal of Clinical Epidemiology, Volume 41, issue 2 (1988), p. 105-114.ISSN: 0895-4356 DOI: 10.1016/0895-4356(88)90084-4 Elsevier Science

2 Rae PICA "Physical Education for Young Children" (Human Kinetics 2008)

${ }^{3}$ NASPE National association for Sport and Physical Education 2000 "Active start: A statement of physical activityguidlines for children birth to 5 years. Reston,VA: Autor
} 
concept is associated with the percentage of fat, muscle tissue and bone, in other words the ratio of lean tissue to fat. Body composition is an important indicator of human health and his physical fitness. Also this is an opportunity to judge whether if an individual is overweight or obese although not appears so ${ }^{4}$. The obesity can be caused by many factors, such as genetic predisposition, low physical activity and non healthy eating habits. As implied, the determination of body composition is important for the assessment of physical fitness in relation to body weight.

In some elementary schools of Tirana city was conducted a remained at study, the purpose of which was to observe the prevalence of overweight and obesity among 7-8 years old children, and to collect data about Body Composition as one of the components of fitness to children. The methodology used was based on anthropometric skin fold measuring of fat percentage also known as the pinch test. By using a caliper, respective values of skin folds were measured, (figure 1 and 2) in the triceps and subscapulare area, to perform the relevant calculations for each subject.

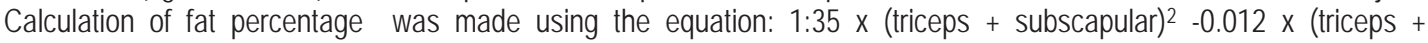
subscapular) ${ }^{2}$ - constant (3.4 males and 1.3 females).(Lohman, 1988) . $^{5}$
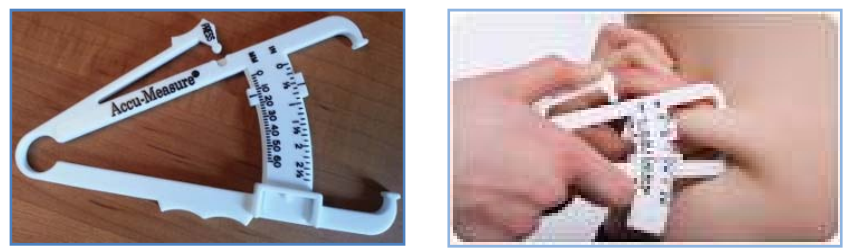

\section{Fig. 1 and 2}

The subjects of this study were 1503 7-8 years old children, students from 11 elementary schools located in different urban areas of the capital (pre-urban and center), "Kongresi i Manastirit", "Osman Myderizi" "26 Nëntori "," Mihal Grameno "," 1 Maj "," Emin Duraku "," Avni Rustem, "Konferenca e Pezës", "Dora d'Istria", "Gustav Mayer" and "7 Marsi". From 1503 children tested, 796 (52\%) of them were male and 707 (48\%) were women, 735 of them form the schools of the center and 768 children from the pre-urban schools. This selection was made in order to ensure a demographic distribution of the subjects tested, to aim to as possible real information, while one of the goals of the study was the comparison and the confrontation of the results between schools from different residential areas, referring to the different lifestyle.

From the data analysis turns out that: in total (males and females) the fat percentage average was $16 \%$, with the maximum value of the data string $36.5 \%$, the minimum value $5 \%$ and mode $11.3 \%$. Referring to the fat percentage Level Chart (Figure 3), 484 children $(\approx 62 \%)$ were in the normal values of fat percentage, $371(\approx 24.9 \%)$ were overweight and obese, $15.9 \%$ of these were females (fat percentage value from 25.9 to $36.5 \%$ ) and $8.7 \%$ were males (with fat percentage value from 20.9 to $34.6 \%$ ). 198 subjects ( $\approx 13.1 \%$ ) were at limits of risk with percentage values from 20 to $24.9 \%$ fat, $8.5 \%$ of these were females and $4.6 \%$ were males.(Chart 1 )

FEMALES (\%)

\begin{tabular}{|l|l|l|l|l|}
\hline Age & Underfat & Healthy & Overfat & Obese \\
\hline 7 & $0-14.9$ & $15-24.9$ & $25-28.9$ & $29+$ \\
\hline 8 & $0-14.9$ & $15-25.9$ & $26-29.9$ & $30+$ \\
\hline 9 & $0-15.9$ & $16-26.9$ & $27-30.9$ & $31+$ \\
\hline 10 & $0-15.9$ & $16-27.9$ & $28-31.9$ & $32+$ \\
\hline 11 & $0-15.9$ & $16-28.9$ & 29.92 .9 & $33+$ \\
\hline 12 & $0-15.9$ & $16-28.9$ & $29 .-32.9$ & $33+$ \\
\hline 13 & $0-15.9$ & $16-28.9$ & 20.92 .9 & $33+$ \\
\hline 14 & $0-15.9$ & $16-29.9$ & $30-33.9$ & $34+$ \\
\hline 15 & $0-15.9$ & $16-29.9$ & $30-33.9$ & $34+$ \\
\hline 16 & $0-15.9$ & $16-29.9$ & $30-33.9$ & $34+$ \\
\hline 17 & $0-15.9$ & $16-28.9$ & $30-33.9$ & $35+$ \\
\hline 18 & $0-16.9$ & $17-30.9$ & $31-35.9$ & $36+$ \\
\hline 19 & $0-18.9$ & $19-31.9$ & $32-36.9$ & $37+$ \\
\hline
\end{tabular}

\section{$\operatorname{MALE}(\%)$}

\begin{tabular}{|c|c|c|c|c|}
\hline Age & Underfat & Healey & Overtat & Chese \\
\hline 7 & M.23 & 13.19.4 & MAS & 134 \\
\hline 6 & 6.123 & 192001 & शมक्र & 3tt \\
\hline 9 & 0.121 & 12811 & 2128: & 20 \\
\hline 10 & M21 & $13-231$ & 2.:37. & 210. \\
\hline 11 & 6.121 & 11921 & 214ล고 & 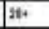 \\
\hline 12 & 0.012 & 12921 & म21, & $3 n$ \\
\hline 12 & ans & 124.1 & nass & $n$ \\
\hline 14 & $0+14$ & 120061 & \$2146! & Iit. \\
\hline 4 & D.60s & 11901 & सर्या & 204 \\
\hline 16 & Ms & 10-19.4 & 20213 & 24. \\
\hline 19 & oss & 16:101 & IMn: & 24 \\
\hline 18 & 609 & 18.101 & 2tats & $5 a t$ \\
\hline 10 & MS & Mas & 2023 & 24 \\
\hline
\end{tabular}

${ }^{4}$ Rae PICA "Physical Education for Young Children" (Human Kinetics 2008)

5 Vivian H. Hayward "Advanced fitness assessment and exercises prescription" Second Edition, Human Kinectics. 2002 
Figure $3^{6}$

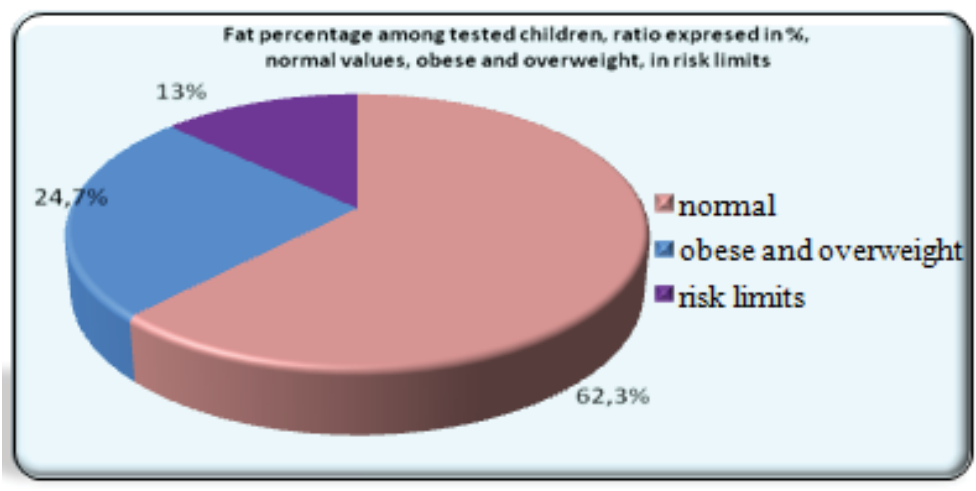

\section{Chart 1}

At females, the average fat percentage was $18.9 \%$, with the maximum value of the data string $36.5 \%$, the minimum $7.2 \%$ and mode $14.9 \%$. From 707 subjects, $338(\approx 47.9 \%)$ were in normal values of fat percentage, $240(\approx 33.9 \%)$ fat percentage values 25.9 to $36.5 \%$ (overweight and obese) and 129 ( $\approx 18.2 \%$ ) in values from 25 to $25.9 \%$ (in risk limits). In males the average fat percentage was $15.9 \%$, with the maximum value of the data string $34.9 \%$, the minimum $5 \%$ and mode $10.9 \%$. From 796 subjects, $569(\approx 75 \%)$ were in the normal values of percentage fat, $131(\approx 16.4 \%)$ fat percentage values 20.9 to $34.6 \%$ (overweight and obese) and $96(\approx 8.6 \%)$ in values from 20 to $20.9 \%$ (in the limits of risk).Chart 2

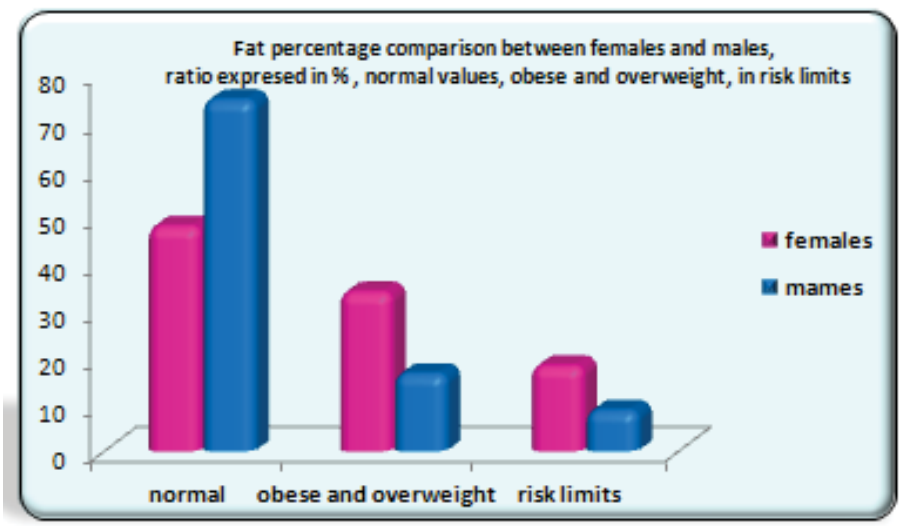

\section{Chart 2}

If we compare the data between schools from pre-urbane areas and schools from the center, from 337 female subjects from pre-urban schools, $273(55.5 \%)$ were in normal values of the percentage fat, 64 ( $\approx 18.9 \%)$ obese and overweight 73 $(\approx 21.6 \%)$ in the risk limits. From 370 female subjects from center schools, $196(\approx 53 \%)$ were in normal values of fat percentage, $118(\approx 31.9 \%)$ overweight and obese, and $56(\approx 15.1 \%)$ in the risk limits. Chart 3

\footnotetext{
${ }^{6}$ Agostini A. PhD , The Coalition To Defeat Childhood Obesity, Inc.(501c3) "Children And Adolescents Body Fat Percentage (\%) Levels" (This Level Chart prepared by Dr.A.Agostini for The Coalition To Defeat Childhood Obesity,Inc.(non-profit),based on information provided by Tanita Ltd.)
} 


\section{Chart 3}

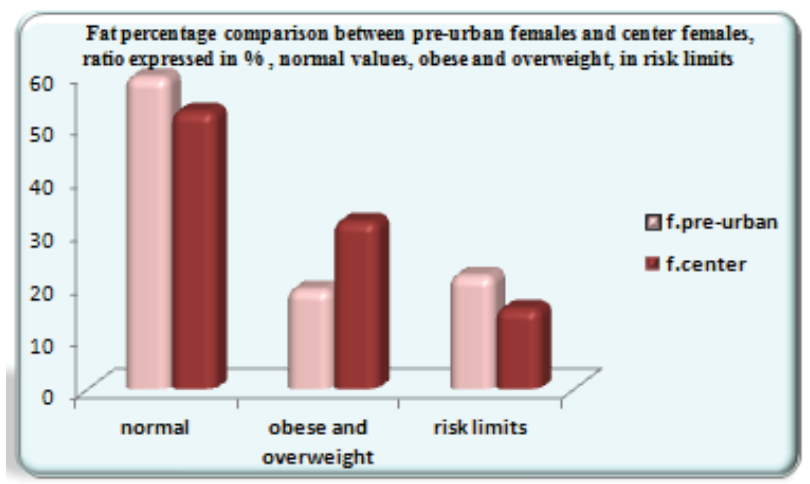

From 431 pre-urban male subjects, $341(\approx 79.2 \%)$ were in normal values of fat percentage, $57(\approx 13.2 \%)$ overweight and obese, and $33(\approx 7.6 \%)$ in the risk limits. From 365 center male subjects, $255(\approx 70 \%)$ were in normal values of percentage fat, $74(\approx 20.2 \%)$ overweight and obese, and $36(\approx 9.8 \%)$ in the risk limits. Chart 4

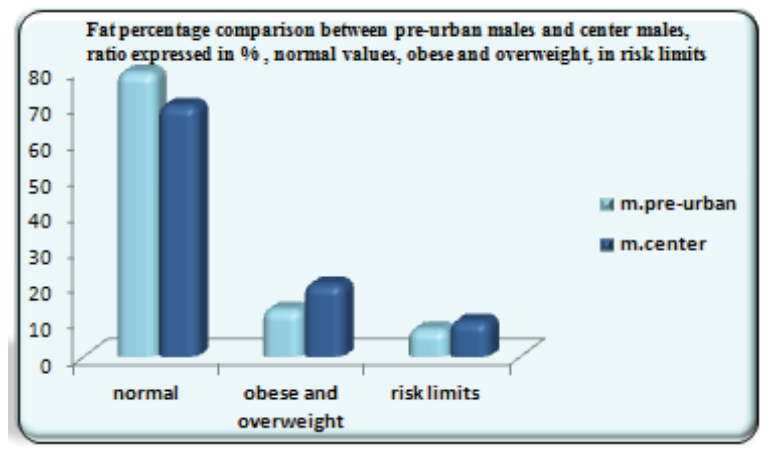

\section{Chart 4}

From 768 male and female pre-urban subjects $\approx 70.5 \%$ of them were in normal values of fat percentage, $\approx 15.7 \%$ were overweight and obese, and $\approx 13.8 \%$ in the risk limits. From 735 male and female center subjects $\approx 61.4 \%$ of them were in normal values of fat percentage, $\approx 26.1 \%$ were overweight and obese, and $\approx 12.5 \%$ in the risk limits. Chart 5

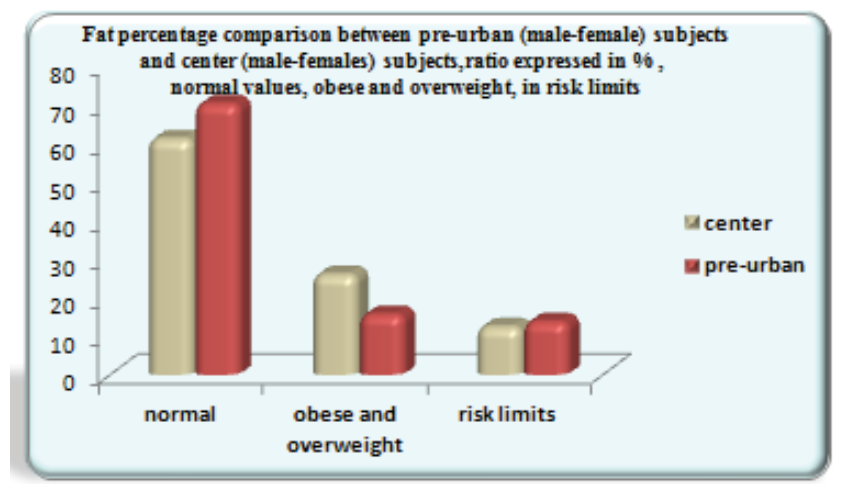

\section{Chart 5}


Referring to the above information :

$>$ The fat percentage average in 1503 subjects tested ( $7-8$ years old children ) was 16\%, 18.9\% to female subject and $15.9 \%$ to male subjects.

$>$ The maximum value of the string is $36.5 \%$ at female subjects (second grade of the obesity) and $34.9 \%$ male subjects (second grade of the obesity).

$>$ A high prevalence of overweight and obesity among the test group, $24.9 \%$ of the tested subjects (males and females) were overweight or obese and $13.1 \%$ are risking limits to be transformed in overweight individuals.

$>$ Of these $15.9 \%$ were females and $8.7 \%$ were males, and in risk limits $8.5 \%$ were females and $4.6 \%$ were males.

$>$ The number of overweight and obese children in the central area is higher than in pre-urban areas, (males and females).

$>$ The number of children with fat percentage in risking limits although the non significant difference was higher among the pre-urban subjects (males and females).

\section{Conclusions}

Although evaluation methods and systems of reference to define the obesity may vary from survey to survey, all studies confirm the rapid growth in the prevalence of overweight and obesity among children and adolescents in many European countries in recent decades, including developing countries such as Albania. The data on overweight and obesity in the presented study indicate a not favorable situation referring to our children in basic education (in elementary schools of the city of Tirana). $24,9 \%$ of the tested subjects (males, females) were overweight or obese, and $13.1 \%$ were in the risking limits to be transformed in overweight individuals, of which $15.9 \%$ females and $8.7 \%$ where males overweight or obese, $8.5 \%$ females in risk limits and $4.6 \%$ males in risk limits (at female subjects there where higher values). Also the fact that the number of children at risk limits of the fat percentage is higher among subjects from pre-urbane areas, shows a negative trend of the spread of the phenomenon expansion in those areas where the lifestyle is different. If the phenomenon of overweight and obesity will continue to increase as this dynamic, then we will have no more differences between different areas of the city, this means a form of "globalization of behaviors", the motor ones (daily physical activity ) as well as the habits and manners of nutrition.

If body composition is not in appropriate ratio, then the child's body does not enjoy the status of fitness, so a child can not be considered "fit". Overweight and obesity are associated with serious complications and illnesses in childhood and adolescence. Overweight and obese young people risk to be overweight and obese adults with diseases such as CVD, hypertension, diabetes mellitus, osteoporosis, functional deficits, etc.. The tree main factors of overweight and obesity are: genetic predisposition, daily dietary intake (the way of feeding) and poor daily energy consumption (physical inactivity), as environmental factors. But the children's feeding mode has not changed during the last decades, while indicators of overweight and obesity increased in value, physical inactivity remains to be the main cause of the rapid growth of overweight and obesity at these age.

\section{Recommendations}

To enable the reduction of the prevalence of overweight and obesity phenomenon in a society should enable the prevention and reduction of it's since his childhood. It is very important that an individual in the early childhood to have a composition body in optimal ratios, where the fat is in the normal value. So it is necessary providing children with a healthy education in nutrition as well as the performance of daily physical activity, necessary to meet the requirements for good health. These requirements impose obligations to the following institutions:

\subsection{The family should:}

Be aware of the irreplaceable role that physical activity plays in the lives of children. So it has to pay more attention to the needs of children for physical activity, whether organized or spontaneous. 
> Limiting the means or ways not very healthy for leisure time passing of their children, as: TV watching (for long hours), playing with electronic tools, etc., and replacing that time with physical games outdoor entertainment, ect.

> Providing personal example, creating a breeding sport for life. Control and upbringing of a healthy breeding feeding, enriching food menu with healthy products, avoiding those canned or hipercaloric foods (like fast food, candies, etc.).

3.2 The school should:

Pay due importance to the Physical Education subject, as the only contact the majority of children in our society have with sports and physical activity.

$>$ Pay particular attention to information and education for a healthy breeding food. Should create greater opportunities for the students to practice physical activity and sports, using better the school's sportive infrastructure.

$>$ Cooperate with parents and other institutions to realize better its policies in this regard.

\subsection{Society and relevant institutions should:}

> Create more facilities and parks, which enable switching active leisure, in the way to help the children to practiced and to gain valuable sportive education, which will be valuable in their life.

$>$ Give the right priority to the Physical Education subject, adding its load curricula.

$>$ Exercise more control over non-nutritious food products that stimulate obesity, sold on the premises inside and outside our schools, enabling a prevention plan.

> Create space for policy development through projects which promote irreplaceable values of physical activity and sport in the lives of each individual.

\section{References}

Agostini A. PhD , "Children and adolescents body fat percentage (\%) levels", The Coalition To Defeat Childhood Obesity, Inc.(501c3).

American Institute Of Medicine. September, 2006. Progress in preventing childhood obesity: How do we measure up? www.iom.edu/Object.File/Master/36/984/11722_report-brief.pdf

Journal of Clinical Epidemiology, Volume 41, issue 2 (1988), p. 105-114.ISSN: 0895-4356 DOI: 10.1016/0895-4356(88)90084-4 Elsevier Science.

Rae Pica "Physical Education for Young Children" (Human Kinetics 2008)

Vivian H. Hayward "Advanced fitness assessment and exercises prescription" Second Edition, Human Kinectics 2002.

World Health Organization, "Obesity and Overweight" Archived from the original on December 18, 2008. Retrieved January 10, 2009.

B.Filippone, C.Vantini, M.Belluci, A.D. Faigenbaum, R. Mario Gulinelli "Trainer's Digest" Movimento, sovrapeso e obesità (Bot. SDS No.72)

Mota.J. "Obesity and Environmental Variables - The Experience of Portugal" IUSM Roma 2006/2007, European Master in Health and Physical Activity.

NASPE National association for Sport and Physical Education 2000 "Praktika lëvizore të përshtatëshme në programe për fëmijët e moshës 3-5 vjec" (fq.12) Reston,VA: Autor

Revue ESP No 330, 331 dhe 332 European Seminar CNAPS, "L'exercice contre les maladies liées à la sédentarité" The first, second and third part. Febuary 2007

Sweeting HN . "Measurement and Definitions of Obesity In Childhood and Adolescence: A field guide for the uninitiated", Nutr. J.6. 2007. 